\title{
PREPROCESSING OF MEASUREMENTS USING SINGULAR SPECTRUM ANALYSIS FOR PARAMETER ESTIMATION OF THE LORENZ SYSTEM
}

\author{
P. E. Oliker ${ }^{1}$, paulineoliker@gmail.com, \\ A. S. Sheludko ${ }^{1}$, sheludkoas@susu.ru. \\ ${ }^{1}$ South Ural State University, Chelyabinsk, Russian Federation
}

\begin{abstract}
The article considers the preprocessing stage of nonlinear parameter estimation. The original data is generated from the Lorenz system, and the measurements are corrupted by an additive noise. Preprocessing of measurements is based on the application of singular spectrum analysis (SSA). The algorithm decomposes time series into additive components. SSA allows to extract components with different dynamics, such as trend, periodic components and noise. In this way, SSA can be used to filtering the measurements. The only parameter of the algorithm is the window length that controls the smoothing level. It is important to choose a proper window length to minimize the error, which defines the difference between the original and the filtered data. Numerical simulations shows that the dependence of the error on the window length has a single minimum, and the optimal values are different for each series of measurements.
\end{abstract}

Keywords: singular spectrum analysis; time series filtering; nonlinear system.

\section{Introduction}

Nonlinear dynamical systems are used for time series modelling and forecasting in natural science, engineering and economics [1]. In all of these fields, the main computational problem is the estimation of the model parameters from experimental data [2]. This article considers the parameter estimation problem for the Lorenz system, which is one of the most widely studied examples of deterministic chaos [3]. The Lorenz system is described by the following equations:

$$
\left.\begin{array}{l}
\dot{x}_{1}(t)=-p_{1} x_{1}(t)+p_{1} x_{2}(t), \\
\dot{x}_{2}(t)=p_{2} x_{1}(t)-x_{2}(t)-x_{1}(t) x_{3}(t), \\
\dot{x}_{3}(t)=-p_{3} x_{3}(t)+x_{1}(t) x_{2}(t),
\end{array}\right\}
$$

where $x_{i}(t), i=1,2,3$ are the state variables, and $p_{i}, i=1,2,3$ are the model parameters. Originally, the system (1) was derived from a model of convection in the atmosphere. But in the past decade, the Lorenz system has been successfully used for secure communication and image encryption [4].

To describe the estimation problem, consider the state space representation of the nonlinear system:

$$
\dot{\mathbf{x}}(t)=\mathbf{f}(\mathbf{x}(t), \mathbf{p}),
$$

where $\mathbf{x}(t) \in \mathbb{R}^{n_{x}}$ is the state vector, and $\mathbf{p} \in \mathbb{R}^{n_{p}}$ is the vector of model parameters. It is assumed that the parameter vector $\mathbf{p}$ is unknown and the measurements of the state vector are corrupted by additive noise:

$$
\mathbf{y}_{k}=\mathbf{x}_{k}+\mathbf{v}_{k}, k=1,2, \ldots, N .
$$


In this notation, $\mathbf{x}_{k} \in \mathbb{R}^{n_{x}}$ is the state vector at discrete time step $k, \mathbf{y}_{k} \in \mathbb{R}^{n_{x}}$ is the measurement vector, $\mathbf{v}_{k} \in \mathbb{R}^{n_{x}}$ is the noise vector, and $N$ is the number of measurements. In the following numerical simulations, the fourth-order Runge-Kutta method is used to obtain the discrete outputs $\mathbf{x}_{k}, k=1,2, \ldots, N$ of the system (2) [5]. The problem is to find the unknown parameter vector $\mathbf{p}$ from measured data (3). Various techniques have been proposed for parameter estimation of nonlinear systems [2]. Since the accuracy of the estimation depends on the noise level, it is possible to improve the results by filtering the measurements.

This article considers preprocessing of measurements using singular spectrum analysis (SSA), which is a useful tool for time series analysis $[6,7,8]$. In $[9,10]$ SSA was applied to the analysis of time series from the Lorenz system (1). Since the input of the SSA is a one-dimensional data, the algorithm is independently applied for each series $y_{i, k}, k=1,2, \ldots, N$ of measurements. The algorithm decomposes time series into additive components. It is assumed that the filtered data $\tilde{x}_{i, k}, k=1,2, \ldots, N$ is the first component that corresponds to the largest singular value of the trajectory matrix. The only parameter of the algorithm is the window length $L$ that defines the dimension of the trajectory matrix and controls the smoothing level. Since the aim of preprocessing is not only to reduce the noise level, but also to minimize the difference between the original and the filtered data, it is important to choose a proper window length.

\section{The Algorithm of SSA}

Consider a one-dimensional time series $y_{k}, k=1,2, \ldots, N$. As mentioned above, the only parameter of the algorithm is the window length $L$, such that $1<L<N$.

Step 1 (Embedding of time series). The result of embedding is the trajectory matrix

$$
\mathbf{Y}=\left(\begin{array}{cccc}
y_{1} & y_{2} & \ldots & y_{N-L+1} \\
y_{2} & y_{3} & \ldots & y_{N-L+2} \\
\vdots & \vdots & \ddots & \vdots \\
y_{L} & y_{L+1} & \ldots & y_{N}
\end{array}\right)
$$

Step 2 (Singular value decomposition). Consider the matrix

$$
\mathbf{S}=\mathbf{Y} \mathbf{Y}^{\mathrm{T}}
$$

The matrix $\mathbf{S}$ can be presented as follows:

$$
\mathbf{S}=\mathbf{U} \boldsymbol{\Lambda} \mathbf{U}^{\mathrm{T}}
$$

where $\mathbf{U}$ is the matrix of eigenvectors $\mathbf{u}_{i}, i=1,2, \ldots, L$, and $\boldsymbol{\Lambda}$ is the diagonal matrix of the corresponding eigenvalues $\lambda_{i}, i=1,2, \ldots, L$. It is assumed that the eigenvalues are ordered by decreasing value:

$$
\lambda_{1} \geq \lambda_{2} \geq \ldots \geq \lambda_{L} \geq 0
$$

Let $n \leq L$ be the number of non-zero eigenvalues. The singular value decomposition of the trajectory matrix (4) can be defined as

$$
\mathbf{Y}=\sum_{i=1}^{n} \mathbf{X}_{i}
$$


where $\mathbf{X}_{i}$ is the elementary matrix given by

$$
\mathbf{X}_{i}=\sqrt{\lambda_{i}} \mathbf{u}_{i} \mathbf{v}_{i}^{\mathrm{T}}, \mathbf{v}_{i}=\frac{\mathbf{Y}^{\mathrm{T}} \mathbf{u}_{i}}{\sqrt{\lambda_{i}}}, i=1,2, \ldots, n .
$$

Step 3 (Grouping). Consider the set $I=\{1,2, \ldots, n\}$ of indices of the elementary matrices. The result of grouping is disjoint subsets $I_{j} \subseteq I, j=1,2, \ldots, m$ such that

$$
I=\bigcup_{j=1}^{m} I_{j} .
$$

Let $\mathbf{X}_{I_{j}}$ be the sum of the elementary matrices $\mathbf{X}_{i}$ with indices from the set $I_{j}$ :

$$
\mathbf{X}_{I_{j}}=\sum_{i \in I_{j}} \mathbf{X}_{i}
$$

Thus, singular value decomposition (5) of the trajectory matrix $\mathbf{Y}$ can be written as follows:

$$
\mathbf{Y}=\sum_{j=1}^{m} \mathbf{X}_{I_{j}}
$$

Step 4 (Diagonal averaging). Let $\mathbf{A}$ be the matrix of dimension $L \times M$. Diagonal averaging converts the matrix $\mathbf{A}$ into times series $x_{k}, k=1,2, \ldots, N$, where $N=L+M-1$. The conversion is defined by the following equations.

If $L<M$ then

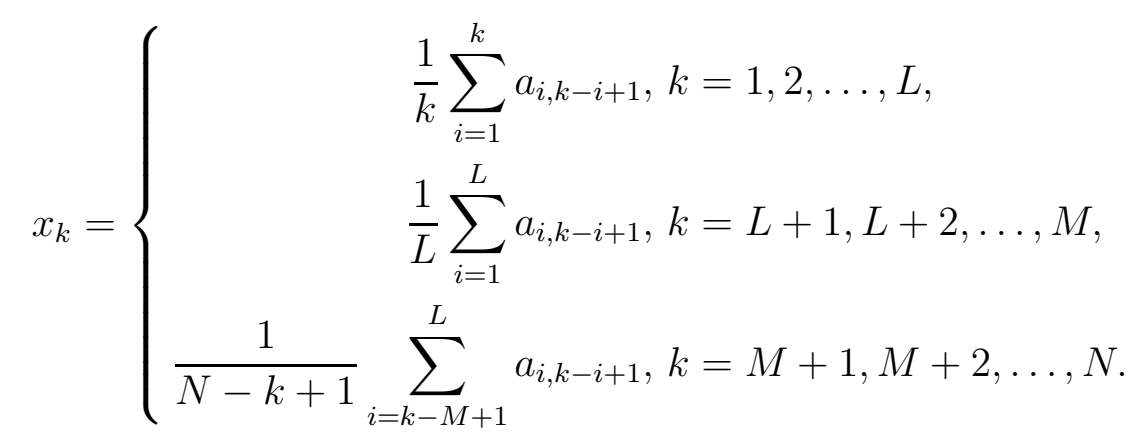

If $L \geq M$ then

$$
x_{k}=\left\{\begin{aligned}
\frac{1}{k} \sum_{i=1}^{k} a_{k-i+1, i}, k & =1,2, \ldots, M, \\
\frac{1}{M} \sum_{i=1}^{M} a_{k-i+1, i}, k & =M+1, M+2, \ldots, L, \\
\frac{1}{N-k+1} \sum_{i=k-L+1}^{M} a_{k-i+1, i}, k & =L+1, L+2, \ldots, N .
\end{aligned}\right.
$$

Diagonal averaging is applied to each matrix $\mathbf{X}_{I_{j}}$ of the decomposition (6). Thus, time series $y_{k}, k=1,2, \ldots, N$ can be decomposed into $m$ additive components:

$$
y_{k}=\sum_{j=1}^{m} x_{k}^{(j)}, k=1,2, \ldots, N .
$$




\section{Numerical Simulations}

The aim of the numerical simulations is to evaluate the dependence of the difference between the original and the filtered data on the window length. In order to obtain averaged results, the tests are run 100 times. Each test consists of the following steps.

Step 1. The original data is generated from the Lorenz system (1) with the parameters $p_{1}=10, p_{2}=28, p_{3}=\frac{8}{3}$. The fourth-order Runge-Kutta method is used with step size $h=0.01$ [5]. In the first test, the initial values are $x_{i}(0)=10, i=1,2,3$. The first 100 outputs are considered as the transient states, and the next outputs are considered as the original data. The number of measurements is $N=400$. In the next tests, the time interval is moved forward by 100 steps. (Fig. 1).

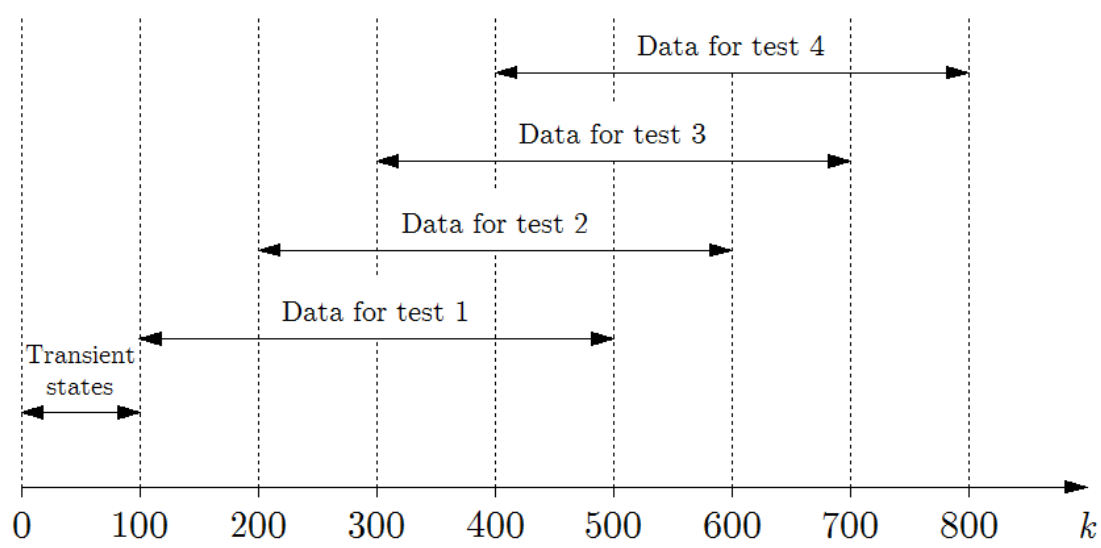

Fig. 1. Choosing the time intervals in the tests

Step 2. The measurements are defined by (3), where each coordinate of the noise vector $\mathbf{v}_{k}$ has normal distribution, zero mean and standard deviation $\sigma=4$. The function randn of Matlab is used as a pseudo-random number generator.

Step 3. SSA is independently applied for each series $y_{i, k}, k=1,2, \ldots, N$ of measurements. In the grouping step, the set $I$ of indices is divided into two subsets $I_{1}=\{1\}$ and $I_{2}=\{2,3, \ldots, n\}$, which correspond to the trend and noise, respectively. The obtained trend is considered as the filtered data $\tilde{x}_{i, k}, k=1,2, \ldots, N$ (see examples in Fig. 2-4). The difference between the original and the filtered data is evaluated by the mean-square error defined as

$$
\delta_{i}=\sqrt{\frac{1}{N} \sum_{k=1}^{N}\left(x_{i, k}-\tilde{x}_{i, k}\right)^{2}} .
$$

This step is performed for each value of $L$ from 5 to 25 . Thus, the result of a single test is dependences of the errors $\delta_{i}, i=1,2,3$ on the window length $L$.

Fig. 5 shows the averaged results. The optimal values are $L_{1}^{*}=11, L_{2}^{*}=9, L_{3}^{*}=8$. This values are used for the examples shown in Fig. 2-4. 


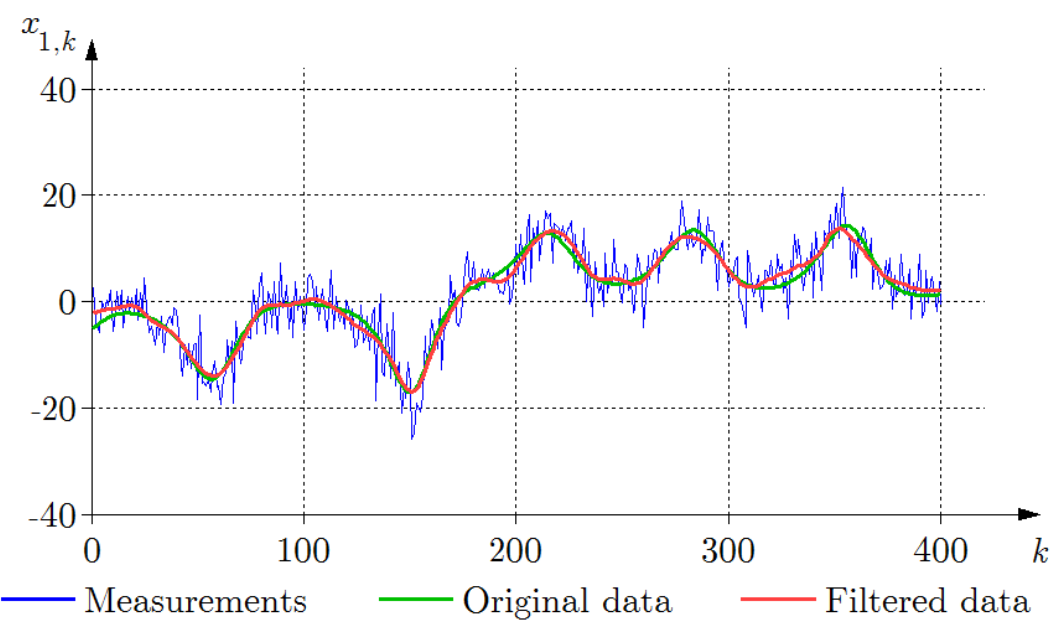

Fig. 2. Preprocessing of measurements of the coordinate $x_{1, k}$

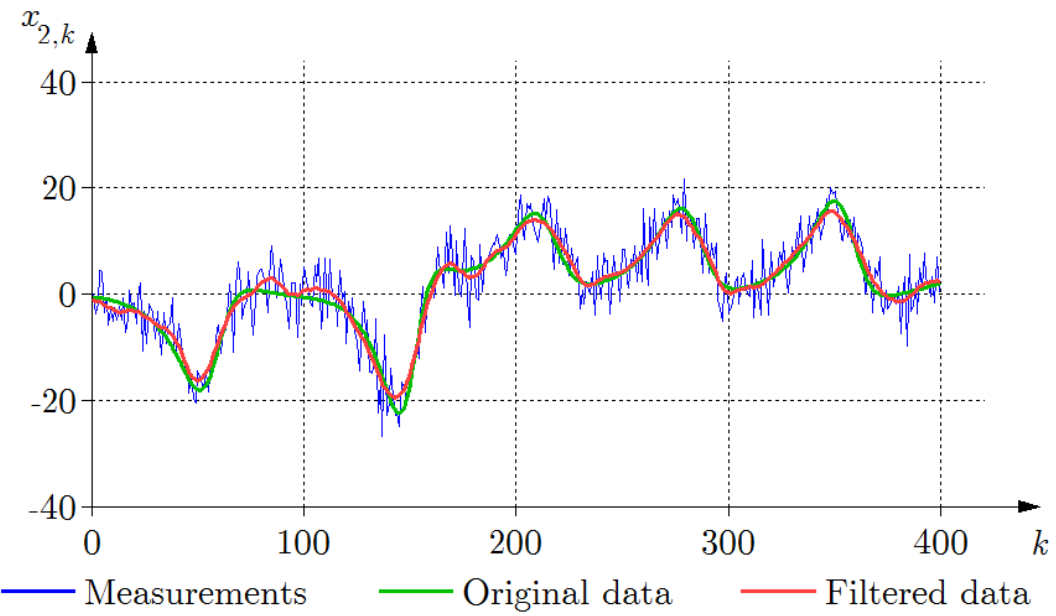

Fig. 3. Preprocessing of measurements of the coordinate $x_{2, k}$

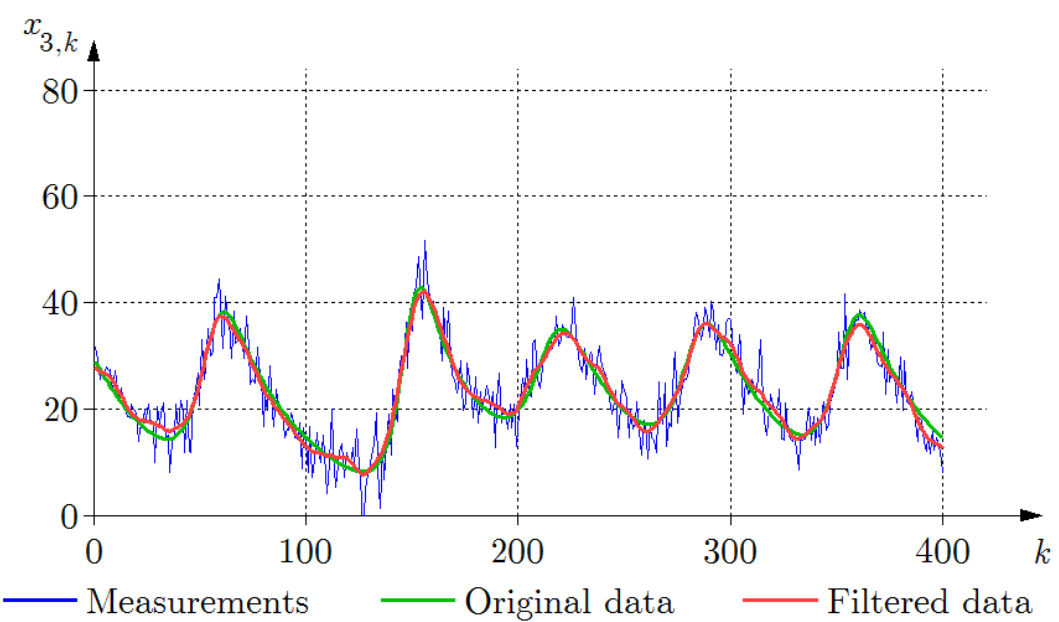

Fig. 4. Preprocessing of measurements of the coordinate $x_{3, k}$ 


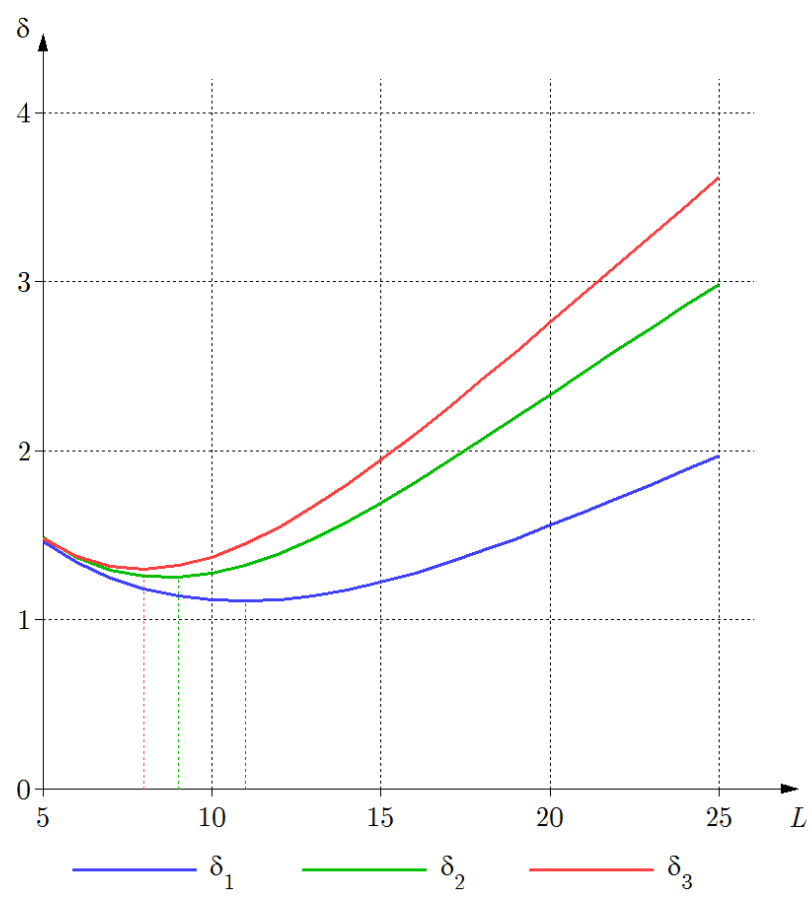

Fig. 5. The dependences of the errors on the window length $L$ (the results are averaged over 100 tests)

\section{Conclusion}

In this article, SSA was applied to time series, which are measurements of the outputs of the Lorenz system. It is assumed that the filtered data is the first components of decompositions (SSA is independently applied for each series of measurements). The result of the numerical simulations is the dependences of the errors, which defines the difference between the original and the filtered data, on the window length $L$. It is shown that each dependence has a single minimum, and the optimal values of $L$ are different for each series.

SSA can be used for preprocessing of measurements to reduce the noise level. But it is important to choose a proper window length, which provides the smallest difference between the original and the filtered data. In addition, SSA has the following advantages.

1. The window length $L$ is the only parameter of the algorithm.

2. The algorithm does not assume that the decomposition components must belong to a certain class.

3. It allows to extract components with different dynamics, such as trend, periodic components and noise.

4. SSA can be applied to short time series $(N<100)$.

The work was supported by Act 211 Government of the Russian Federation, contract no. 02.A03.21.0011. 


\section{References}

1. Bezruchko B. P., Smirnov D. A. Extracting Knowledge From Time Series. An Introduction to Nonlinear Empirical Modeling. Berlin, Heidelberg, Springer, 2010. DOI: $10.1007 / 978-3-642-12601-7$

2. Voss H. U., Timmer J., Kurths J. Nonlinear Dynamical System Identification from Uncertain and Indirect Measurements. International Journal of Bifurcation and Chaos, 2004, vol. 14, no. 6, pp. 1905-1933. DOI: 10.1142/s0218127404010345

3. Sprott J. C. Chaos and Time-Series Analysis. Oxford University Press, 2003.

4. Ozkaynak F. Brief Review on Application of Nonlinear Dynamics in Image Encryption. Nonlinear Dynamics, 2018, vol. 92, pp. 305-313. DOI: 10.1007/s11071-018-4056-x

5. Jiang Y., Lau F. C. M., Wang S., Tse C. K. Parameter Identification of Chaotic Systems by a Novel Dual Particle Swarm Optimization. International Journal of Bifurcation and Chaos, 2016, vol. 26, no. 2, pp. 1650024. DOI: $10.1142 / \mathrm{s} 0218127416500243$

6. Elsner J. B., Tsonis A. A. Singular Spectrum Analysis: a New Tool in Time Series Analysis. Boston, MA, Springer, 1996. DOI: 10.1007/978-1-4757-2514-8

7. Golyandina N., Zhigljavsky A. Singular Spectrum Analysis for Time Series. Berlin, Heidelberg, Springer, 2013. DOI: 10.1007/978-3-642-34913-3

8. Hassani H. Singular Spectrum Analysis: Methodology and Comparison. Journal of Data Science, 2007, vol. 5, no. 2, pp. 239-257.

9. Vautard R., Yiou P., Ghil M. Singular-Spectrum Analysis: a Toolkit for Short, Noisy Chaotic Signals. Physica D: Nonlinear Phenomena, 1992, vol. 58, issues 1-4, pp. 95126. DOI: 10.1016/0167-2789(92)90103-t

10. Vitanov N. K., Sakai K., Dimitrova Z. I. SSA, PCA, TDPSC, ACFA: Useful Combination of Methods for Analysis of Short and Nonstationary Time Series. Chaos, Solitons \& Fractals, 2008, vol. 37, issue 1, pp. 187-202. DOI: $10.1016 /$ j.chaos.2006.08.043

Polina E. Oliker, Undergraduate Student, Department of Applied Mathematics and Programming, South Ural State University (Chelyabinsk, Russian Federation), paulineoliker@gmail.com.

Anton S. Sheludko, MSc(Math), Senior Lecturer, Department of Applied Mathematics and Programming, South Ural State University (Chelyabinsk, Russian Federation), sheludkoas@susu.ru.

Received August 25, 2020. 


\title{
ПРИМЕНЕНИЕ СИНГУЛЯРНОГО СПЕКТРАЛЬНОГО АНАЛИЗА ДЛЯ ПРЕДВАРИТЕЛЬНОЙ ОБРАБОТКИ ИЗМЕРЕНИЙ В ЗАДАЧЕ ОЦЕНИВАНИЯ ПАРАМЕТРОВ СИСТЕМЫ ЛОРЕНЦА
}

\author{
П. Е. Оликер, А. С. Шелудъко
}

\begin{abstract}
В статье рассматривается этап предварительной обработки измерений в задаче оценивания параметров нелинейной модели. Исходные данные являются реализацией системы Лоренца, а измерения - результатом добавления аддитивных ошибок. Предварительная обработка измерений основана на применении сингулярного спектрального анализа (SSA). Результатом алгоритма SSA является разложение временного ряда на аддитивные составляющие. Алгоритм позволяет выделять составляющие с различной динамикой (тренд, периодические колебания, шум), и, таким образом, может быть использован для фильтрации измерений. Единственным параметром алгоритма SSA является длина окна, которая определяет степень сглаживания. При этом важно выбрать оптимальную длину окна, которая минимизирует отклонение данных, полученных после фильтрации, от исходных. Результатом проведенных вычислительных экспериментов является график зависимости отклонения от длины окна. Показано, что данная зависимость имеет единственную точку минимума, а оптимальные значения длины окна различны для каждой серии измерений.
\end{abstract}

Ключевые слова: сингулярный спектральный анализ; фильтрачия временных рядов; нелинейная система.

\section{Литература}

1. Bezruchko, B. P. Extracting Knowledge From Time Series. An Introduction to Nonlinear Empirical Modeling / B. P. Bezruchko, D. A. Smirnov. - Berlin, Heidelberg: Springer, 2010.

2. Voss, H. U. Nonlinear Dynamical System Identification from Uncertain and Indirect Measurements / H. U. Voss, J. Timmer, J. Kurths // International Journal of Bifurcation and Chaos. - 2004. - V. 14, № 6. - P. 1905-1933.

3. Sprott, J. C. Chaos and Time-Series Analysis / J. C. Sprott. - Oxford University Press, 2003.

4. Ozkaynak, F. Brief Review on Application of Nonlinear Dynamics in Image Encryption / F. Ozkaynak // Nonlinear Dynamics. - 2018. - V. 92. - P. 305-313.

5. Jiang, Y. Parameter Identification of Chaotic Systems by a Novel Dual Particle Swarm Optimization / Y. Jiang, F. C. M. Lau, S. Wang, C. K. Tse // International Journal of Bifurcation and Chaos. - 2016. - V. 26, № 2. - P. 1650024.

6. Elsner, J. B. Singular Spectrum Analysis: a New Tool in Time Series Analysis J. B. Elsner, A. A. Tsonis. - Boston, MA: Springer, 1996.

7. Golyandina, N. Singular Spectrum Analysis for Time Series / N. Golyandina, A. Zhigljavsky. - Berlin, Heidelberg: Springer, 2013. 
8. Hassani, H. Singular Spectrum Analysis: Methodology and Comparison H. Hassani // Journal of Data Science. - 2007. - V. 5, № 2. - P. 239-257.

9. Vautard, R. Singular-Spectrum Analysis: a Toolkit for Short, Noisy Chaotic Signals / R. Vautard, P. Yiou, M. Ghil // Physica D: Nonlinear Phenomena. - 1992. - V. 58, iss. $1-4 .-$ P. $95-126$.

10. Vitanov, N. K. SSA, PCA, TDPSC, ACFA: Useful Combination of Methods for Analysis of Short and Nonstationary Time Series / N. K. Vitanov, K. Sakai, Z. I. Dimitrova // Chaos, Solitons \& Fractals. - 2008. - V. 37, № 1. - P. 187-202.

Оликер Полина Евгенъевна, студент, кафедра прикладной математики и программирования, Южно-Уральский государственный университет (г. Челябинск, Российская Федераиия), paulineoliker@gmail.com.

Шелудъко Антон Сергеевич, магистр математики, старший преподаватель, кафедра прикладной математики и программирования, Южно-Уральский государственный университет (е. Челябинск, Российская Федерация), sheludkoas@susu.ru.

Поступила в редакиию 25 августа 2020 г. 